\title{
Eight
}

\section{ANTHROPOCENTRISM, CONSERVATISM, AND GREEN POLITICAL THOUGHT}

\section{Introduction}

In his article, "Consider the Squirrel: Freaks, Vermin and Value in the Ruin(s) of Nature," Nicholas Holm argues that environmentalism naturally tends towards socially conservative logics. If this is true, then we have to question what seems otherwise to be a natural fit between the agendas of environmental protection and the other laudable social goals that environmentalists usually support. Non-violence, de-militarisation and disarmament, participatory democracy, social justice: while it is possible for one to be an environmentalist and not particularly care about these things, in practice we typically find that those who care about the environment also have "progressive" views on these issues, as is certainly evinced by the parliamentary wings of the Green movement (Green Party of Canada, "Platform;" Green Party of Aotearoa New Zealand, "More Issues;" Bündnis 90/Die Grünen, "Uns Geht's Ums Ganze;" Aria-Maldonado 2007, 234). But perhaps this is purely contingent. If the Green movement and Green political thought is based on a fundamentally conservative logic, we might find that socially progressive policy and environmental protection are in tension at quite a deep level, and that green activity towards socially progressive ends is ultimately undermined by this.

In this paper I will examine a number of justifications for environmental concern, and show why all except for the (broadly) anthropocentric demonstrate problematic conservative logics that incline them towards socially conservative positions. Environmentalists would do best to take up an anthropocentric, or at least anthropogenic, defence of green values if they want to pair it with a progressive social politics. This is not to say that environmentalists are, in practice, socially conservative. Deep democracy, for example, or an emphasis on grassroots democratisation, political mobilisation and community involvement in decision-making, is something that tends to be favoured by Greens (Dobson 2007, 106; Benton 1993, 38). Those for whom environmental sustainability and care are a core part of their politics typically oppose corporate-bureaucratic systems that operate outside democratic political institutions (Grove-White 1993, 27). The 'father of conservatism', 
Edmund Burke, on the other hand, considered the impulse to extend democratic participation as widely as possible savage, "the literal death of Western civilization (O’Neill 2007, 127; Burke 1968, 372)." In addition, whereas Burke's conservatism was "entirely satisfied [with] the inequality which grows out of the nature of things by time, custom, succession, accumulation, permutation, and improvement of property (Burke 1852, 403)," Greens tend to be in favour of social justice issues, such as gender equality (Warren 1990), Lesbian, gay, bisexual and transgender rights, and the rights of the poor and marginalised (Bullard \& Johnson 2000; Datye 1997, 42). Environmentalist organisations such as Green Cross advocate strongly for nuclear non-proliferation, arms control, and disarmament (Green Cross, "Nonproliferation, Arms Control, Disarmament"). Despite the occasional concern shown by organisations such as the conservative New Zealand National Party's "Bluegreens" working group, Greens do not usually actually advocate for conservative causes in practice (NPPAGEC, "Bluegreens").

I am not arguing in this paper, therefore, that environmentalists tend also to be conservatives. Rather, following Holm, I suggest that the conservative logics that can underlie the Green view, if we understand it in particular ways, can cause a tendency towards social conservatism. If we justify our environmental concern in the problematic ways I outline, but conservatism is resisted in terms of social policy, there is some cognitive dissonance between the Green environmental and social views. Given the Green focus on the environment, there is good reason to think that there is not a necessary connection, or even a natural affinity, between Green thought and social justice goals. It certainly seems that, often enough, social justice goals are instrumentally useful for Greens, given that the environment is their central focus - arguably the environment, as an empirical matter, tends to be protected better when social justice is also protected (Porritt 2005, 10). If this tension between the social and environmental features of Green thought continues, Greens may advocate for social justice goals, when it suits them but they also may not. This tension between social justice and environmentalism exists for Greens on a fundamental level, even if they do not often have to confront it. However, sometimes we might truly have to trade one value off against the other.

Green opposition to interference in the environment can be understood in four main ways, only one of which, I argue, manages to avoid conservative tendencies. First, we understand Green opposition to interference with the environment as the preservation of an underlying order to nature itself. Second, Greens act so as to maximise diversity, usually in the form of a concern for biodiversity specifically. Third, Greens can justify environmental protection based on the precautionary principle, which bids us to take care when making drastic changes to complex systems. Finally, environmental protection is justified on anthropocentric grounds; that is, due to the benefit it has for us (or, if we were to be slightly broader, the benefit to non-human 
animals, though still due to the features that we value in humans). According to this view, we protect the environment because it achieves our own goals, and actualises our own values. In the following sections, I will briefly examine each position and its implications for green politics that are compatible with socially progressive politics. Ultimately I argue that we should adopt an anthropocentric justification for environmental concern. This does not necessarily rest on a mere interest in continued economic growth, on the argument that our future economic health rests on a healthy environment (though I would certainly agree that this is this case). Instead, it is a matter of deciding what it is that we value (as opposed to claiming the intrinsic value of certain things), preferably through open public deliberation, and acting so as to bring about such values.

\section{An Underlying Order}

The view that there is an underlying order to nature that we ought to respect is the most obviously conservative of the alternatives outlined above. In fact, it is directly analogous to Burke's own view. According to Burke, there is an underlying order to the social world that we tamper with at our peril. Certainly, basing their opposition on the idea of an underlying order would make environmentalists, along with Burke, at the very least anti-radical. According to this view, "[n]either man nor nature starts each day and age de novo. Instead, both build on what has gone before, and in building sustain, in sustaining renew" (Pappin 1993, 86). The radical approach, in contrast, is that problems with the current order cannot be solved within the framework of that order, and a fundamentally new order must take its place.

This does not mean that change can never occur. It is not change per se that is the problem: change is essential, if we want to avoid a static, atrophied world. However, Burke believed that changes ought to be made "without violence to essential structures... throughout these changes, something [should remain] abiding, substantially and essentially unchanged" (Pappin 1993, 78). For conservatives, radicals "do not recognize the good that exists and, in their impatience to cure the evil, destroy the good without replacing it with the better" (Freeman 1980, 3).

An opposition to substantial change on the grounds of damage to underlying structures does seem to be a perspective contrary to that of progressive politics. As Andrew Dobson writes:

Since the French Revolution it has been a theme of left-wing thought that the existence of a concrete natural order of things with which human beings should conform and not tamper is a form of medieval mumbojumbo used by the right to secure and ossify privilege (Dobson 2007, 19). 
Environmentalist thought that aims at the preservation of this underlying nature shares troubling logics with social conservatism. If there is, as Holm puts it, a "sense that there exist 'proper' forms and arrangements of nature" (Holm 2012, 58), without the necessity of specifying precisely what it is that is valuable about such an order aside from its mere existence, then change away from the present (or prior idealised) state is always degradation, never improvement.

We could argue that the underlying order develops over time, and this historical development is what we need to preserve. It is certainly the case that if the physical environment is built through aeons of accumulated endeavour, we cannot possibly hope to rival it in many respects through our rational design. We simply cannot hope to capture the complexity of the underlying order of nature through our engineering (Botkin 1990, 102-3). Anything we do to this nature-as-wilderness is, therefore, taking it from a more ideal to a less ideal state of affairs.

But all this is done without at any point needing to elaborate on what is good about this underlying order; its value is intrinsic, not derived from its meeting certain criteria of value. This view is clearly based on conservative logics, and one could argue that Burke would be in complete agreement with it (Freeman 1980,3). After all, if we are concerned with the development over time of complex systems that, unobstructed, create an ideal underlying order, and we see as destructive any radical attempts to engineer such an order, why restrict this just to the physical environment? Society, too is an extremely complex system, well beyond our ability to engineer with any kind of precision or confidence. Society has also developed through processes that are outside our explicit control. By the same reasoning we ought to hesitate to change anything in society lest we risk undermining the underlying, intrinsically valuable social order. In short, if we want to attribute an underlying order to nature, we cannot easily avoid the same logic applying to society as well.

\section{Diversity}

An alternative to the belief in an underlying order is to claim that we ought to avoid interference with the natural world because doing so undermines its diversity. This is, in some ways, very similar to having an underlying order, except it provides a more definite account of what it is we find valuable in such an order. Rather than just somewhat unreflexively advocating for a particular order merely because it is the one that has happened to develop historically, the biodiversity approach supports any order, human-built or natural, that maximises biological diversity. As it happens, the biodiversity that develops when there has been no human interference, when the order is 'natural', tends to be more diverse than when the order has been interfered with significantly by human beings: "historically, ecosystems that have been 
significantly altered by human beings are less complex" (DeLancey 2012, 27). There are certainly exceptions, such that the re-wilding of former wilderness can sometimes bring about a superior state of affairs. Nevertheless, generally it is the case that evolution, when left alone, "tends to maximize the number and kinds of organisms in a region" (DeLancey 2012, 28).

This approach certainly has more in favour of it than the underlying order account. Certainly, if it were the case that proponents of biodiversity aimed at diversity above all else in practice, and that we could agree that this is what we should ultimately value, this view would escape the conservatism found in the underlying order account. However, this is generally not the case: as Holm points out, "while biodiversity might imply a desire to maximize difference in the natural world, in practice it tends to focus on the preservation of difference as it currently exists" (Holm 2012, 61). It is more concerned with "rendering the present eternal - moving ourselves and our planet out of the flow of history" (Bowker 2004, 112). There is a tension between the support for biodiversity, in terms of preserving the current distribution of plants and animals, and the opposition to global warming, which might, after all, increase biodiversity in the long run, if we consider that the biodiversity of the world was higher when we had temperate forests in the Arctic (Bowker 2004, 112). In other words, if supporters of biodiversity were consistent in holding that biodiversity is the ultimate value, they might be obliged to support activities that lead to climate change.

Preserving the current diversity rather than considering alternate states of affairs that might have more diversity overall, though composed of different entities in different arrangements, is merely another iteration of the conservative logic underpinning the underlying order account. On the other hand, truly attempting to maximise diversity at all costs, ignoring its effect on currently existing organisms, is troublingly callous. We do tend to think that the entities that exist have some kind of higher status than merely possible entities. Hence, advocates for biodiversity must either compromise their view that biodiversity has a deep, fundamental value or, if they truly advocate for biodiversity, abandon all concern for the organisms that currently exist in order to bring about whatever ideal state does in fact maximise biodiversity, possibly including a warmed world.

\section{The Precautionary Principle}

Is it necessary to have underlying order or a commitment to diversity in mind when opposing change? Rather than opposing certain kinds of change, can environmentalists avoid Holm's critique by instead opposing rates of change? After all, just because change is necessary, this does not "imply that all changes, regardless of time, intensity, and rate, are desirable" (Botkin 1990, 71). In this understanding, when environmentalists oppose change it is not necessarily to preserve a certain state of affairs; rather, they can oppose 
change because it operates on such a scale that the effects are drastic and unpredictable. As Craig DeLancey points out,

It is simply a fact that we can change a landscape - cut the trees, plow the Earth, irrigate it, drain it, poison it, mine it, invert it - many times faster than most genotypes can adapt to such changes (DeLancey 2012, $33)$.

In other words, we ought to be cautious when making changes where the outcome might be very different than what we expect. The scale of our activities are so great that our actions have truly global, and potentially irreversible, consequences, and we have very little reason to have confidence that we understand the natural world well enough to alter it in predictable ways. The furore over the spread of genes from genetically modified corn to wild non-modified varieties is a case in point (Stewart, Halfhill \& Warwick 2003). Our increasingly potent ability to alter the world together with our lack of knowledge leads to the precautionary principle: "If we cannot know the outcome of an intervention in the environment but suspect that it may be dangerous, then we are best advised... not to intervene at all" (Dobson 2007, 59).

Unfortunately, the precautionary principle might not be able to do as much work as we would like, as it cannot be limited in principle just to environmental caution. Certainly the same line of thinking can be applied to social issues as well. Burke may have believed that there is an underlying order that we should not tamper with, but there is no reason he had to have thought so in order to maintain his conservative prescriptions. Social conservatives can, and in fact often do, utilise the precautionary principle just as easily to justify their opposition to progressive social change as they can by pointing to an underlying order. For example, it is equally straightforward to oppose gay marriage due to its potential to cause drastic and unpredictable change to society as it is to oppose it due it supposedly being an attack on the 'natural' order.

If we believe that our knowledge of the environment is still incomplete, and that we should therefore proceed with caution in altering it, the same could be said of change to our social systems. We just do not know for sure what the long-term social impacts will be in extending the definition of marriage to include homosexual couples. Social progressives certainly have confidence that the outcome will be positive, and there are a lot of good reasons to think it will be. But if we are to be honest we have to admit that the complexity of social changes means that, despite our confidence and despite the probably-well-deserved scorn heaped on the conservative moral panic about marriage equality, we just cannot know for sure. The precautionary principle, due to the fact that it can be equally-well mobilised to block social change as environmental change, does not allow us to avoid Holm's charge 
that environmentalism relies on conservative logics, or at the very least incline in that direction.

\section{Anthropocentrism}

There is one account (or, really, family of accounts) that can give a determinate sense to the precautionary principle, yet is not underpinned by conservative logics: Greens ought to oppose intervention in the natural environment because it has negative consequences for human beings, prevents human being from achieving their ends, or works against our ability to actualise our values. This anthropocentric account adopts features from the alternatives, yet is justified on different grounds. For example, it may indeed be that an underlying order has developed over time, but we should not advocate for such an order merely for its own sake, because it has 'intrinsic' value, but because we know that such an order works for us. What, exactly, it means for something to 'work for us' is a matter for discussion amongst those affected by the order; nevertheless, this is something that can, in principle, be settled. Such values are ours; they are not based on the intrinsic value of a particular underlying order, or a particular history. We can imagine alternative states of affairs that work for us equally well based on such criteria. We can provide an account of what it would mean for a society to work for us, and we can imagine different societies that better actualise these values. We can also find that our values change over time, perhaps due to including more points of view (the perspective of animals, perhaps?), or due to rethinking our fundamental commitments based on public reasoning and criticism. States of affairs judged in regards to our anthropogenic values are at least potentially criticisable and revisable: we can openly discuss whether we should, after all, hold such values, whether states of affairs are to the good, and whether and how we can weigh specific goods against each other.

In the context of biodiversity, we can support the maximisation of diversity, but instead of this being merely for its own sake, and hence having no regard for the organisms that currently exist, we can instead see nonhuman entities as having value in the same way that humans do, and hence the right to life. At first blush this may seem non-anthropocentric, but in fact our concern for non-human life must be based on what we see as valuable to humans. As Stephen Avery puts it, our concern for non-human life is based on a deep anthropocentrism that relies on "a connection between humans and the world, a connection that has roots in the human condition" (Avery 2004, 32 , italics mine). That is, if what we see as giving rights to human beings, or creating our duties to them, or providing them with dignity, is also found in the non-human world, then the non-human world has value too. As we would not approve of the extinction of a culture for the instrumental end of diversity in the long run, we ought not treat a species in this way (though what gives a species value - whether this is due to its benefit to the individuals of which 
the species is composed, or is something intrinsic - is a matter of debate) (Agar 1995).

Finally, an anthropocentric account allows us to determine which states of affairs we should be cautious to avoid. If we base our account on anthropocentric value, we can have an open discussion about whether the potential costs of an activity outweigh the benefits, rather than simply opposing all change. Certainly, the persistence of the human species is generally, if not universally, something we value (though perhaps it does not have any value if we were not around to value it) (Overall 2012, 192-4). Greens argue that "the scale of human activity relative to the biosphere's capacity to absorb and sustain it has increased to the point where long-term human survival and the biosphere's integrity are put in doubt" (Dobson 2007, 24). There is, then, "no grounds for supposing that we are not in the position of the proverbial man, falling from a 20 -storey building, who was heard to call out 'so far so good' as he passed the sixth floor" (Benton 1994, 36). A lack of caution is dangerous for us and for the continued actualisation of our own values: considering the scale and novelty of our interventions in the natural world, and our misplaced trust in our own competence, we could say, not entirely unreasonably, that many of our large-scale activities have at least a fair chance of being dangerous and counter-productive in terms of our own goals and values. Hence, we can quite easily argue that the costs of businessas-usual in terms of our environmental impact do not outweigh the benefits, while consistently holding that marriage equality, or nuclear disarmament, or distributive equality, are worth the risk of potential downsides.

None of the above accounts suffer from conservative logics provided that they are ultimately grounded in anthropogenic value rather than the supposed intrinsic value of the natural world. An underlying order can be valued instrumentally, but if we claim it has value intrinsically, or because of a history that has intrinsic value, we slide in conservative logics. If we want to support biodiversity and socially progressive politics, thinking in anthropocentric terms helps us to justify valuing the current distribution of organisms on non-arbitrary terms. Finally, we can apply the precautionary principle with a much more determinate sense of what we want to achieve with it: it is not just change that we oppose, but change that undermines our ability to reach our goals and actualise our values. There are specific kinds of changes that are unwelcome, as well as specific kinds that might be very welcome indeed. Hence, if we as environmentalists want to avoid, at the very least, cognitive dissonance between our support for environmental protection and progressive politics, and at worst a tendency for the movement to unwittingly adopt socially conservative political positions in the long run, we ought to justify our concerns with anthropocentric values. 


\section{WORKS CITED}

Agar, Nicholas. (1995) "Valuing Species and Valuing Individuals" Environmental Ethics 17: 4 (Winter), 397-415.

Aria-Maldonado, Manuel. (2007) "An Imaginary Solution? The Green Defence of Deliberative Democracy" Environmental Values 16: 2 (May), 233-252.

Avery, Stephen. (2004) "The Misbegotten Child of Deep Ecology" Environmental Values 13: 1 (February), 31-50.

Benton, Ted. (1994) "Biology and Social Theory" in Michael Redclift \& Ted Benton, eds., Social Theory and the Global Environment. London and New York: Routledge.

Botkin, Daniel B. (1990) Discordant Harmonies: A New Ecology for the Twenty-First Century. New York: Oxford University Press.

Bowker, Geoffrey C. (2004) "Time, Money, and Biodiversity" in Aihwa Ong \& Stephen J. Collier, eds., Global Assemblages: Technology, Politics, and Ethics and Environmental Problems. Malden, MA.: Blackwell.

Bullard, Robert D. \& Glenn S. Johnson. (2000) "Environmental Justice: Grassroots Activism and Its Impact of Public Policy Decision Making" Journal of Social Issues 56: 3, 555-578.

Bündnis 90/Die Grünen, "Uns Geht's Ums Ganze" Accessed 11th April, 2013. https://www.gruene-bundestag.de/servicenavigation/english_ID_2000025.html

Burke, Edmund. (1852) The Works and Correspondence Of Edmund Burke, Volume 3. London: F. \& J. Rivington.

Burke, Edmund. (1968) Reflections on the Revolution in France. Harmondsworth: Pelican Books.

Cronon, William. (1995) "The Trouble with Wilderness; or, Getting Back to the Wrong Nature," in William Cronon, ed., Uncommon Ground: Rethinking the Human Place in Nature. New York: W.W. Norton \& Co.

Datye, K.R. with Suhas Paranjape \& K.J. Joy. (1997) Banking on Biomass: A New Strategy for Sustainable Prosperity based on Renewable Energy and Dispersed Industrialization. Ahmedabad, India: Centre for Environment Education, Nehru Foundation for Development.

DeLancey, Craig. (2012) "An Ecological Concept of Wilderness" Ethics \& the Environment 17: 1 (Spring), 25-44.

Dobson, Andrew. (2007) Green Political Thought, 4th edition. London: Routledge.

Freeman, Michael. (1980) Edmund Burke and the Critique of Political Radicalism. Oxford: Basil Blackwell.

Green Cross, "Nonproliferation, Arms Control, Disarmament," Accessed 11th April, 2013. http://www.gcint.org/what-we-do/nonproliferation-armscontrol-disarmament 
Green Party of Aotearoa New Zealand, "More Issues," Accessed 21 December, 2013. https://www.greens.org.nz/campaigns/all

Green Party of Canada, "Platform," Accessed 21 December, 2013. https://www.greenparty.ca/

Grove-White, Robin. (1993) "Environmentalism: A New Moral Discourse?" in Kay Milton, ed., Environmentalism: The View from Anthropology. London: Routledge.

Holm, Nicholas. (2012) "Consider the Squirrel: Freaks, Vermin, and Value in the Ruin(s) of Nature" Cultural Critique 80: 1 (Winter) 56-95.

National Party Policy Advisory Group for Environment and Conservation, "Bluegreens," Accessed 11th April, 2013. http://www.bluegreens.org.nz/

O'Neill, Daniel I. (2007) The Burke-Wollstonecraft Debate: Savagery, Civilization, and Democracy. University Park, PA: Pennsylvania State University Press.

Overall, Christine. (2012) Why Have Children? The Ethical Debat. Cambridge, MA: MIT Press.

Pappin, Joseph L. (1993) The Metaphysics of Edmund Burke. New York: Fordham University Press.

Porritt, Jonathon. (2005) Capitalism: As If the World Matters. London: Earthscan.

Stewart, C. Neal, Jr., Matthew D. Halfhill \& Suzanne I. Warwick. (2003) "Genetic modification: Transgene introgression from genetically modified crops to their wild relatives" Nature Review Genetics 4 (October), 806-817.

Warren, Karen. (1990) "The Power and Promise of Ecological Feminist," Environmental Ethics 12: 2 (Summer), 125-146. 